Article

\title{
Environmental and Economic Performance of Yacon (Smallanthus sonchifolius) Cultivated for Fructooligosaccharide Production
}

\author{
Moritz Wagner ${ }^{1, *(\mathbb{D})}$, Larissa Kamp ${ }^{2}$, Simone Graeff-Hönninger ${ }^{2} \mathbb{D}$ and Iris Lewandowski ${ }^{1}$ \\ 1 Department Biobased Products and Energy Crops, Institute of Crop Science, University of Hohenheim, \\ 70599 Stuttgart, Germany \\ 2 Institute of Crop Science, University of Hohenheim, 70599 Stuttgart, Germany \\ * Correspondence: moritz.wagner@uni-hohenheim.de; Tel.: +49-0711-459-23557
}

Received: 21 July 2019; Accepted: 21 August 2019; Published: 23 August 2019

check for updates

\begin{abstract}
As the prevalence of diabetes is predicted to rise globally in the coming decades, the demand for sugar substitutes is expected to increase significantly. In this context, natural sweeteners have been receiving particular attention, as artificial sweeteners have been associated with obesity and cardiovascular disease. One natural sweetener is yacon (Smallanthus sonchifolius) ((Poepp. and Endl.) H. Robinson), which could play a prominent role due to its high fructooligosaccharides yield. Yacon is currently only a minor crop in Europe and there is little information available on the environmental and economic impacts of its various cultivation systems. These are especially affected by nitrogen fertilization levels and genotype selection. Thus, before the crop is introduced on a larger scale, it is expedient to identify the most sustainable cultivation system. The life-cycle assessment (LCA) and life-cycle costing (LCC) analysis of yacon cultivation systems conducted in this study revealed significant differences between yacon genotypes and found that a nitrogen fertilization level of $80 \mathrm{~kg} \mathrm{~N} \mathrm{ha}^{-1}$ significantly decreased production costs and simultaneously led to a comparatively good environmental performance. The results indicated that, for the holistic evaluation of agricultural systems, it is crucial to assess both the economic and environmental performance of new crops.
\end{abstract}

Keywords: yacon; fructooligosaccharides; environmental performance; LCA; production cost; LCC

\section{Introduction}

Yacon (Smallanthus sonchifolius) ((Poepp. And Endl.) H. Robinson) is a tuberous root plant belonging to the family Asteraceae. It is a herbaceous perennial plant with a height of up to $2.5 \mathrm{~m}$ that originates from the Andean region [1], where it is cultivated as a staple food for local consumption and as a cash crop [2,3]. In addition to its region of origin, yacon is also cultivated in Brazil, Czech Republic, Italy, Japan, and New Zealand [4,5]. It can achieve tuber yields of up to $67 \mathrm{t}$ fresh matter (FM) ha ${ }^{-1}$ [6]. The tuberous roots, which have a dry matter content of between $10 \%$ and $18 \%$, act as storage organs for the plant [6-9]. Similar to Jerusalem artichoke and chicory, yacon stores carbohydrates primarily as fructan, in particular as fructooligosaccharides (FOS), with FOS accounting for up to $70 \%$ of the dry matter content [10]. The FOSs in yacon consist mainly of kestose, nystose, and fructofuranosylnystose [7]. The high fructooligosaccharide content makes yacon an interesting resource for the food processing industry. FOSs cannot be digested by the human intestinal tract and therefore do not lead to an increase in blood glucose level. For this reason, yacon can be used as a natural sweetener for diabetics [11]. Due to its high tuber yield and interesting properties, yacon could offer European farmers a promising opportunity to increase crop diversity.

In recent years, several publications have assessed the influence of genotype selection and cultivation practice on yacon tuber yields and composition [6,8,12-15]. Kamp et al., for example, 
showed that nitrogen fertilization had an influence not only on the tuber yield but also on the fructooligosaccharide content of the tubers [6]. An increase in nitrogen fertilization levels led to an increase in both tuber yields and the FOS content of the tubers, and therefore also to an increase in total FOS yield per hectare. However, an increase in nitrogen fertilization was also accompanied by an increase in environmental impact, for example through nitrate leaching, and additional costs for the farmer. Furthermore, it has been shown that different propagation techniques lead to considerable differences in both propagations costs and tuber yields [14].

Thus, before this novel food crop is introduced on a larger scale, it is necessary to consider which yacon cultivation system is the most beneficial from both an environmental and economic point of view. Despite the growing importance of FOS-producing crops, there are currently no studies on the environmental performance of yacon cultivation. With regard to its economic performance, only the economic feasibility of the different propagation methods has been analysed to date [14]. For this reason, the current paper assesses the economic and environmental performance of entire yacon cultivation systems. In line with the sustainable intensification approach, the aim is to find cultivation systems which increase the yacon tuber yield and quality, while minimizing negative environmental impacts and production costs [16]. In addition, it identifies possible trade-offs between environmental and economic factors and discusses possible mitigation options.

The environmental performance of yacon-based FOS production was assessed by conducting a life-cycle assessment (LCA), according to the ISO standards 14040 and $14040[17,18]$, and applying the life-cycle impact assessment methodology ReCiPe [19]. The selection of the relevant environmental impact categories was based on Wagner et al. [20], who analysed the relevance of various impact categories in the assessment of the environmental performance of agricultural production systems. Their study recommended including the impact categories climate change (CC)—which corresponds to global warming potential-agricultural land occupation (ALO), marine (ME) and freshwater eutrophication (FE), human toxicity (HT), as well as marine (MET) and freshwater ecotoxicity (FET) [20]. The economic performance was analysed in a complementary life-cycle cost (LCC) assessment, in accordance with Swarr et al. [21]. The data for the yacon cultivation were based on a field trial at Ihinger Hof, a research station of the University of Hohenheim, as described in Kamp et al. [6]. The FOS content of the yacon tubers was analysed by high performance liquid chromatography (HPLC). Background data on emissions and costs associated with input substrates (e.g., fertilizer), machine use, and transport processes were taken from the ecoinvent database 3.5 [22] and from the KTBL database [23].

\section{Materials and Methods}

\subsection{Scope and Boundaries}

The functional unit chosen was $1 \mathrm{~kg}$ of fructooligosaccharide contained in the yacon tubers at the farm gate. The further FOS extraction process was not included here.

The system assessed in this study is displayed in Figure 1. The system boundaries included the production and transport of the input substrates used, such as mineral fertilizers and herbicides, the production of the propagation material, and the agricultural management (soil cultivation, ridging, planting, fertilization, herbicide spraying, harvesting), including diesel consumption of the respective process steps. After soil cultivation and fertilizer application, ridges were formed, into which the yacon plantlets were then transplanted. Chemical weed control was performed twice, once before planting and once during the growth period. After the harvest, which was performed using a modified potato harvester, the tubers and rhizomes were separated by hand. The rhizomes were stored until the next year to be used for propagation of new plantlets in the greenhouse. 


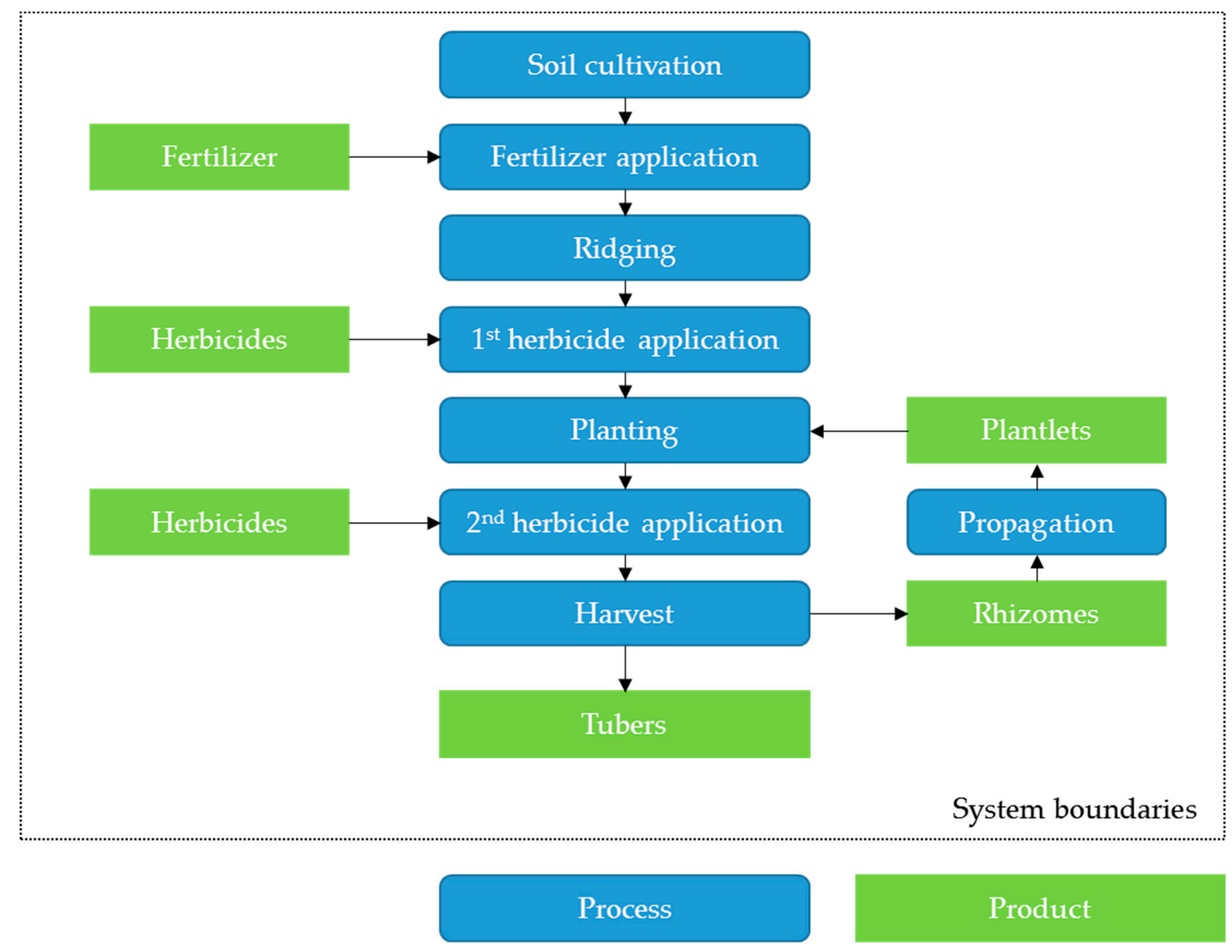

Figure 1. System description and boundaries for yacon cultivation.

\subsection{Life-Cycle Inventory}

The study was based on the results of a field trial where yacon was cultivated under three nitrogen fertilizer regimes at the Ihinger Hof, a research station of the University of Hohenheim $\left(48^{\circ} 44^{\prime} \mathrm{N}\right.$, $8^{\circ} 55^{\prime} \mathrm{E}$ and 475 a.s.l.) in southwest Germany [6]. Before planting, soil preparation was performed once with a plough and twice with a tine cultivator. At the beginning of May, the yacon plantlets were transplanted by hand into the ridges (height $\times$ width: $60 \times 45 \mathrm{~cm} ; 44 \mathrm{~cm}$ between ridges) with a plant density of 12,531 plants $\mathrm{ha}^{-1}$. Plantlets were obtained from rhizome pieces pre-cultivated for six to eight weeks in the greenhouse before being planted. The field trial evaluated the tuber yield formation of two yacon genotypes: a brown-shelled (BG) and a red-shelled genotype (RG). The yacon genotypes are described more in detail in Kamp et al. [6]. In addition, three nitrogen fertilization levels were investigated: 0, 40, and $80 \mathrm{~kg} \mathrm{~N} \mathrm{ha}^{-1}$. In the field trial of Kamp et al. [6], ENTEC 26 was applied as nitrogen fertilizer. ENTEC 26 (EuroChem Agro GmbH, Mannheim, Germany) is a stabilized fertilizer consisting of $26 \%$ total nitrogen (18\% ammonium nitrogen, $7.5 \%$ nitrate nitrogen) and $13 \%$ hydro soluble sulphur, with nitrification inhibiter 3,4-dimethyl-1H-pyrazole phosphate (DMPP). The $\mathrm{N}_{\min }$ in the soil prior to planting was $119 \mathrm{~kg} \mathrm{NO}_{3} \mathrm{ha}^{-1}$ [6]. The life-cycle inventory also included the application of $100 \mathrm{~kg}$ potassium in form of potassium sulphate, according to the fertilization recommendation of Singh [24]. It has been shown that potassium fertilization has positive effects on the yield and quality of tuberous root plants [25]. The potassium fertilization was the same for all nitrogen fertilisation levels analysed in this assessment. In yacon, weed control has to be applied [26]. The current study made the assumption that chemical weed control was applied using $1.251 \mathrm{ha}^{-1}$ Dual Gold (Syngenta, active ingredient $960 \mathrm{~g} \mathrm{l}^{-1} \mathrm{~S}$ Metolachlor) as a pre-emergence herbicide before planting and $3.51 \mathrm{ha}^{-1}$ Stomp Aqua (BASF, active ingredient $455 \mathrm{~g} \mathrm{l}^{-1}$ Pendimethalin) as a post-emergence 
herbicide. Furthermore, it was assumed that all input substrates were transported $150 \mathrm{~km}$ from their production sites to the farm by truck and $2 \mathrm{~km}$ to the field by tractor. In practice, yacon is harvested in October with a modified potato or carrot harvester. The results of the field trial showed significant differences in yield between the two genotypes and the three nitrogen levels [6]. The dry matter yield, FOS content, and FOS yield for the different fertilization levels are displayed in Table 1. The data used in the current study resulted from the year 2017. In Kamp et al. [6], the results for the field trials are displayed for 2016 and 2017. However, in 2016 a different propagation system was used, therefore the current assessment includes only the yield data and yacon tuber characteristics from the year 2017.

Table 1. Dry matter yield, fructooligosaccharide (FOS) content, and FOS yield of the yacon genotypes, with three different nitrogen fertilization levels. Establishment was carried out using standard procedure, i.e., planting of pre-cultivated plantlets. Data from Kamp et al. [6].

\begin{tabular}{|c|c|c|c|c|c|c|}
\hline \multirow{2}{*}{$\begin{array}{l}\text { Input/Output } \\
\text { Fertilization level in } \mathrm{kg} \mathrm{N} \mathrm{ha}^{-1}\end{array}$} & \multicolumn{3}{|c|}{ Red-Shelled Genotype } & \multicolumn{3}{|c|}{ Brown-Shelled Genotype } \\
\hline & 0 & 40 & 80 & 0 & 40 & 80 \\
\hline Tuber yield in kg DM ha $\mathrm{ha}^{-1}$ & 10,350 & 10,496 & 11,405 & 4716 & 4515 & 5672 \\
\hline FOS content in $\%$ & 30.50 & 33.23 & 34.81 & 36.21 & 39.35 & 42.02 \\
\hline FOS yield in kg FOS $\mathrm{ha}^{-1}$ & 3157 & 3488 & 3970 & 1708 & 1777 & 2383 \\
\hline
\end{tabular}

In the harvesting process, both the yacon tubers and rhizomes are harvested. As a consequence, there is no risk of yacon re-sprouting in the follow-on crop. In addition, the cold winter temperatures in southwest Germany would destroy any plant material left, as yacon is a non-frost tolerant crop [1]. After the harvest, the tubers have to be manually separated from the rhizomes. The rhizomes are wrapped in perforated bags and stored in lightproof boxes, filled with a mixture of sand and sawdust to absorb humidity. The following year, the rhizomes are sliced into smaller pieces, which are then propagated in the greenhouse, as described in Kamp et al. [14]. This procedure is referred to as "standard procedure" in the following text. It results in a yield of 15 pieces per rhizome. Therefore approximately 836 rhizomes are required to obtain the necessary planting density of 12,531 plants ha ${ }^{-1}$. In the current study, it was assumed that the farmer buys new rhizomes every 10 years to acquire novel yacon genotypes and keep up with breeding progress. The costs of purchasing 836 rhizomes were allocated to the 10 years in which the genotype was used.

Fertilizer-induced emissions during the cultivation process were estimated as described below. Direct $\mathrm{N}_{2} \mathrm{O}$ and $\mathrm{NO}$ emissions from nitrogen fertilizer were calculated according to Bouwman et al. [27]. Indirect $\mathrm{N}_{2} \mathrm{O}$ emissions from nitrogen fertilizer and $\mathrm{N}_{2} \mathrm{O}$ emissions from harvest residues were calculated based on emission factors taken from Intergovernmental Panel on Climate Change (IPCC) [28]. Nitrogen-fertilizer-induced ammonia emissions were estimated according to EMEP/CORINAIR emission inventory guidebook [29]. Phosphate and phosphorus emissions to surface and ground water were estimated based on Nemecek and Kägi [30]. Nitrate leaching to ground water was calculated according to the emission factors taken from IPCC [28]. All pesticides applied were modelled completely as emissions to agricultural soil, in accordance with Nemecek and Schnetzer [31]. The ecotoxicity values for the herbicides applied were taken from the ecoinvent database [22]. In the field trials, a fertilizer with nitrification inhibitors was used (ENTEC 26). The resulting emission reductions were calculated for direct $\mathrm{N}_{2} \mathrm{O}$ and $\mathrm{NO}$ emissions according to Akiyama et al. [32] and for nitrate leaching according to Díez López and Hernaiz [33].

The costs of machinery and diesel used in the agricultural operations were based on the KTBL database [23]. The related labour costs were calculated using the working time requirements for each agricultural operation specified by KTBL [23]. Hourly wages of $€ 17$ were assumed based on calculations by the North Rhine-Westphalia chamber of agriculture and the German agricultural labour agreement [34]. These labour costs included incidental wage costs. An annual land rent of $€ 328$ per hectare was applied. This was based on the average cost of leasing agricultural land in Germany in the year 2016 [35]. Background data associated with the transport of the input substrates, transport costs 
for the yacon tubers, and herbicide costs were taken from the ecoinvent database 3.5 [22]. Potassium and ENTEC 26 fertilizer costs were based on market prices [36,37]. The cost assumptions used are described more in detail in the supplementary material. The costs of the agricultural operations are given in Table S1 and those of the input substrates in Table S2. The costs of biomass transport are shown in Table S3 and details of costs associated with the propagation process are given in Table S4.

\subsection{Scenario Analysis}

In the standard procedure, plantlets are obtained from rhizome pieces pre-cultivated for six to eight weeks in the greenhouse before being planted. This pre-cultivation step is quite labourand energy-intensive. It has been demonstrated that the direct planting of rhizomes can potentially decrease propagation process costs substantially, but that the tuber yield is also considerably lower [14]. According to Kamp et al. [14], a yield reduction of up to 30\% can occur. For this reason, the influence of direct rhizome planting on the economic and environmental performance of yacon cultivation was assessed in a scenario analysis. In this scenario (direct planting), the rhizomes were planted directly into the soil with a modified potato planter and the FOS yield was reduced by $30 \%$ compared to the standard procedure (as displayed in Table 1).

\section{Results}

The results of the life-cycle cost analysis are presented first, followed by the life-cycle assessment.

\subsection{Life-Cycle Cost Analysis}

The life-cycle costs of the red-shelled (RG) and brown-shelled genotypes (BG) are given in Euro per kg FOS (Figure 2). In addition, in Table S5 in the supplementary, they are given per tonne FM. There are considerable differences between the two genotypes. The production costs of the brown-shelled genotype are almost twice as high as for the red-shelled genotype. This is caused by the significantly lower FOS yield of the brown-shelled genotype. A comparison of the different treatments showed that the increase in FOS yield caused by additional nitrogen fertilizer led to a significant decrease in costs. In addition, despite the lower yield, direct planting was associated with lower production costs. This is true for both genotypes (see Figure 2). However, the differences between the standard procedure and direct planting were quite small.

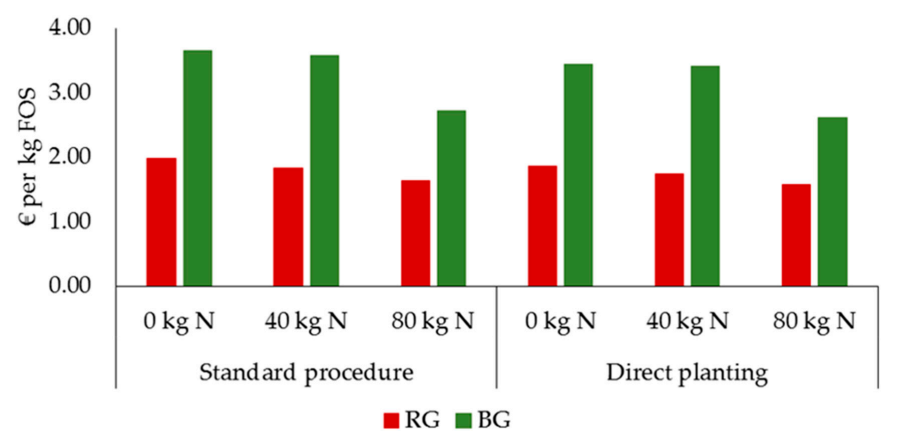

Figure 2. Yacon production costs in Euro per kg FOS for the red-shelled (RG) and the brown-shelled genotype (BG).

Figure 3 shows the distribution of the costs for the standard procedure and direct planting. For both treatments, the results are displayed for the red-shelled genotype and the fertilization level $40 \mathrm{~kg} \mathrm{~N} \mathrm{ha}^{-1}$. Here, "production input material" includes the production of all fertilizers and pesticides. "Agricultural operations" incorporates all steps from soil cultivation through to harvest, including the separation of tubers and rhizomes. "Propagation" includes the storage of the rhizomes and propagation in the greenhouse. "Transport biomass" incorporates the transport of the yacon tubers and rhizomes from the field to the farm. 


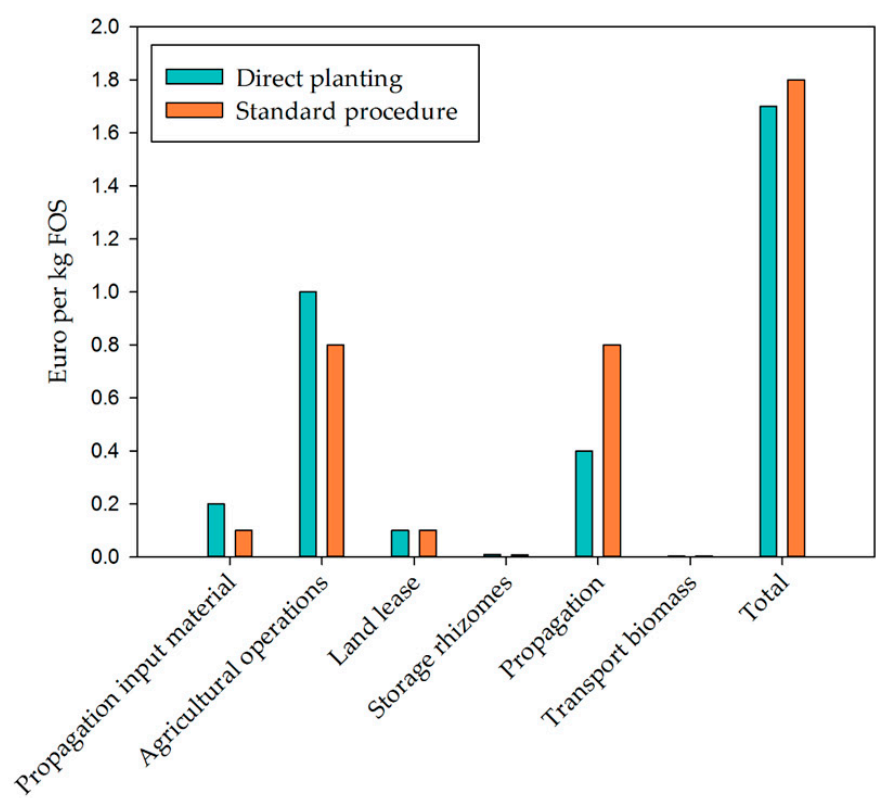

Figure 3. Distribution of yacon production costs in Euro per $\mathrm{kg}$ FOS (here shown only for the red-shelled genotype and the $40 \mathrm{~kg} \mathrm{~N}^{-1}$ fertilization level).

The yacon production costs are dominated mainly by the costs of agricultural operations and propagation (Figure 3). The agricultural operations costs are incurred to a large extent from the yacon planting and harvest. There are considerable differences between the two treatments. The most pronounced difference can be seen in the step "propagation". Propagation costs are dominated by labour costs (e.g., due to the slicing of the rhizomes) as well as by costs for greenhouse infrastructure and operation, which are not incurred in direct planting.

\subsection{Life-Cycle Assessment}

For the seven impact categories assessed, the environmental impacts are expressed per functional unit (FU) of $1 \mathrm{~kg}$ FOS (Figures 4-6). In addition, in Table S5 in the supplementary materials they are given per tonne FM. In the category marine eutrophication, the environmental impact increased with an increase in nitrogen fertilization. The standard procedure showed lower results than for direct planting and thus had a more favourable environmental performance (Figure 4).

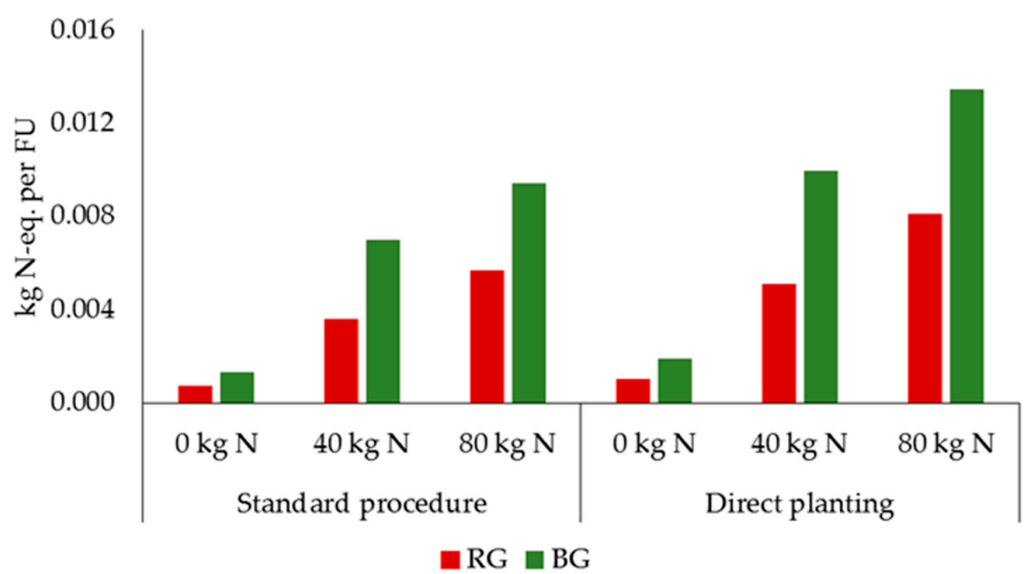

Figure 4. Marine eutrophication (kg N-eq.) per kg FOS for the red-shelled (RG) and the brown-shelled genotype (BG). 

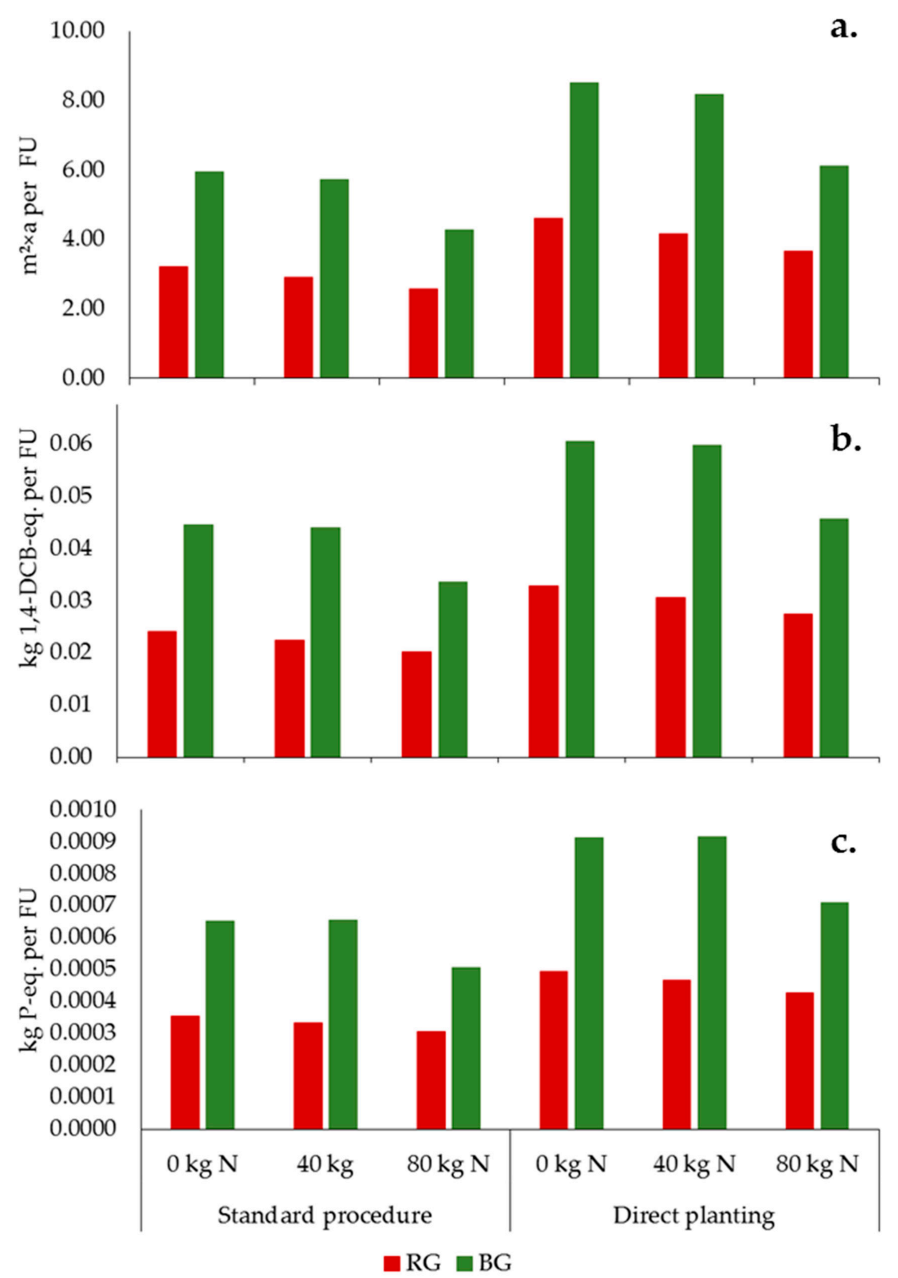

Figure 5. (a) Agricultural land occupation $\left(\mathrm{m}^{2} \times \mathrm{a}\right)$, (b) freshwater ecotoxicity (kg 1,4-DCB-eq.), (c) freshwater eutrophication potential (kg P-eq.) per kg FOS for the red-shelled (RG) and the brown shelled genotype (BG).

By contrast, in the impact categories agricultural land occupation, freshwater ecotoxicity, and freshwater eutrophication, an increase in nitrogen fertilization level led to a decrease in the respective environmental impacts per FU. This was true for both propagation methods, the standard procedure and direct planting (Figure 5).

The life-cycle impact assessment results for the impact categories climate change, human toxicity, and marine ecotoxicity are shown in Figure 6. For the brown-shelled genotype, the $40 \mathrm{~kg} \mathrm{~N} \mathrm{ha}^{-1}$ fertilization level resulted in the highest environmental impacts per kg FOS in all three categories. The differences in the environmental performance between the 0 and $80 \mathrm{~kg} \mathrm{~N} \mathrm{ha}^{-1}$ fertilization levels were comparatively small (Figure 6). For the red-shelled genotype, the assessment showed a slight increase in the impact categories climate change and human toxicity with increasing nitrogen fertilization. In the category marine ecotoxicity, the $40 \mathrm{~kg} \mathrm{~N} \mathrm{ha}^{-1}$ fertilization level showed the highest impacts for the red-shelled genotype. The 0 and $80 \mathrm{~kg} \mathrm{~N} \mathrm{ha}^{-1}$ levels are comparable. 

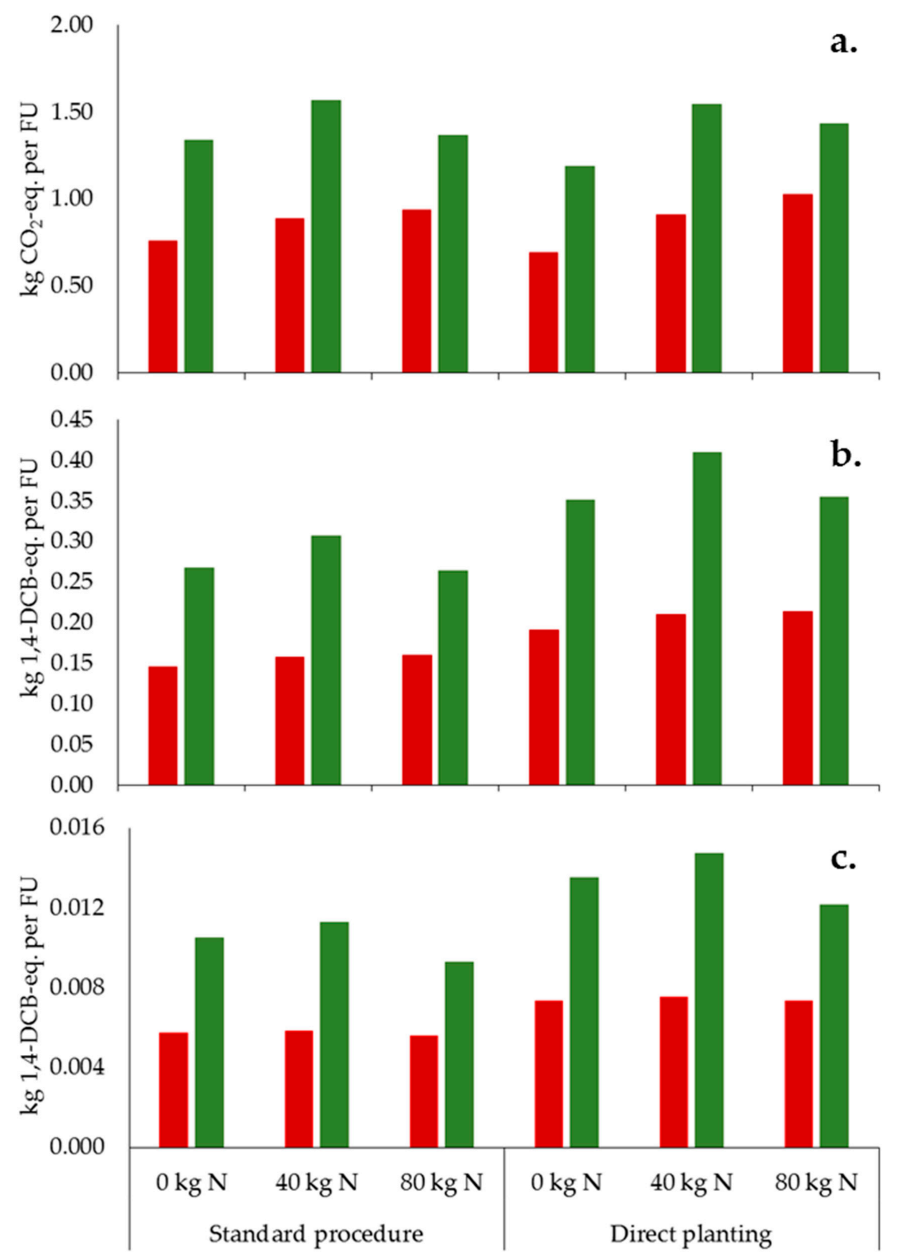

$\square \mathrm{RG} \square \mathrm{BG}$

Figure 6. (a) Climate change (kg CO 2 -eq.), (b) human toxicity ( $\mathrm{kg}$ 1,4-DCB-eq.), (c) marine ecotoxicity (kg 1,4-DCB-eq.) per kg FOS for the red-shelled (RG) and the brown shelled genotype (BG).

\subsection{Hotspot Aanalysis}

A hotspot analysis of the economic and environmental performance of yacon cultivation for FOS production is displayed in Figure 7. Results are shown for the $40 \mathrm{~kg} \mathrm{~N} \mathrm{ha}^{-1}$ fertilization level for the red-shelled genotype planted in the standard procedure. Here, "production input material" includes the production of all fertilizers and pesticides. "Agricultural operations" incorporates all steps from soil cultivation through to harvest, including the separation of tubers and rhizomes. The "agricultural system" includes the land use of the yacon cultivation as well as all fertilizer-induced emissions. "Propagation" refers to the storage of the rhizomes and the propagation in the greenhouse. "Other" includes land rent and all costs and environmental impacts associated with the transport of the biomass from the field to the farm.

There are considerable differences between the major contributors to the costs and environmental impacts. Whereas the life-cycle costs of FOS production are dominated by costs for propagation and agricultural operations, the environmental impacts are strongly influenced by the agricultural system (Figure 7). ALO is almost exclusively dominated by the agricultural system, i.e., the land used for cultivation. By contrast, the impact of the agricultural system in the category climate change is mainly caused by nitrogen fertilizer production (contained in production input material) and nitrogen-fertilizer-induced emissions, such as $\mathrm{N}_{2} \mathrm{O}$. Fertilizer-induced emissions are also main contributors to the impact categories ME (nitrate emissions to ground water), FE (phosphate and phosphorus emissions to surface and ground water), and FET (phosphorus emissions to surface water). 


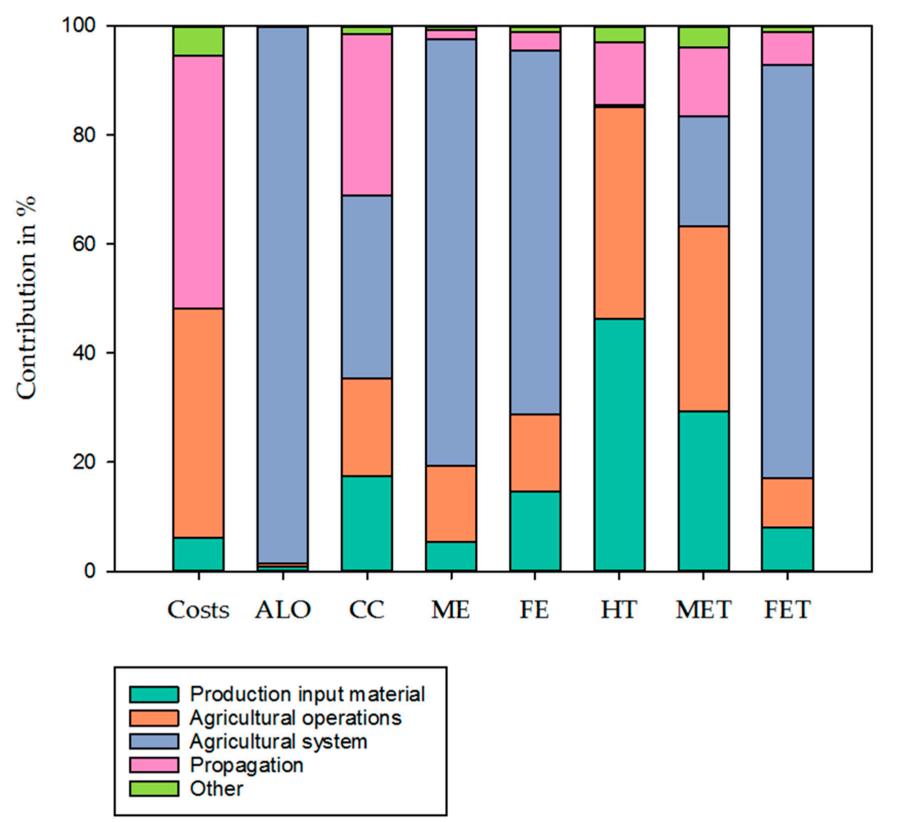

Figure 7. Hotspot analysis of the economic and environmental performance of yacon cultivation for FOS production (results are shown for the $40 \mathrm{~kg} \mathrm{~N} \mathrm{ha}^{-1}$ fertilization level of the red-shelled genotype planted in the standard procedure). ALO = Agricultural land occupation; $\mathrm{CC}=$ Climate Change; $\mathrm{ME}=$ Marine eutrophication; FE = Freshwater eutrophication; HT = Human toxicity; MET = Marine ecotoxicity; FET = Freshwater ecotoxicity.

\section{Discussion}

The first part of the discussion provides a critical analysis of the environmental and economic performance of yacon-based FOS production. Here, possible trade-offs are identified between life-cycle costs and environmental impact categories, as well as between the environmental impacts themselves, the main hotspots are highlighted, and potential improvements suggested. The second section focuses on the question of which yacon cultivation system makes the most sense from an environmental and economic point of view and can be recommended for introduction into agricultural practice in Europe.

\subsection{Environmental and Economic Performance of Yacon-Based FOS Production}

The results of the environmental and economic assessment of the different yacon production procedures revealed that a high FOS yield is the key to low negative environmental impacts with simultaneous low costs.

It is this higher FOS yield that led to both lower environmental impacts and life-cycle costs per $\mathrm{kg}$ FOS in the red-shelled rather than the brown-shelled genotype, independent of treatment and propagation method. Although the brown-shelled genotype had a higher percentage FOS content, the lower tuber yields resulted in considerably lower FOS yields per hectare compared to the red-shelled genotype. As the vast majority of costs and environmental impacts remained the same per hectare regardless of the FOS yield, the red-shelled genotype had a superior economic and environmental performance per kg FOS.

The study showed that there were only relatively small differences in production costs per $\mathrm{kg}$ FOS between the two propagation methods "standard procedure" and "direct planting". In "standard procedure", significantly higher propagation costs for the greenhouse cultivation of plantlets were incurred. These were avoided to a large extent in "direct planting", leading to slightly lower production costs per $\mathrm{kg}$ FOS, despite the $30 \%$ yield gap. However, with regard to the environmental performance, direct planting led to considerably higher impacts in all categories assessed. This is because, although the propagation method had a huge influence on production costs (as explained above), it had only minor impacts on the environmental performance in most impact categories. It was shown that the 
cost-intensive manual labour involved in the propagation method standard procedure did not lead to environmental impacts. Therefore, the two propagation methods had comparable environmental impacts per hectare, but these impacts had to be allocated to considerably different yield levels. As a result, the standard procedure had a better environmental performance per $\mathrm{kg}$ FOS produced. This study assumed a 30\% yield reduction for direct planting, in accordance with Kamp et al. [14]. However in other field trials, the recorded yield reduction was considerably smaller. In a study conducted by Doo et al. [38], the yield for the direct planting of yacon rhizomes was only $5 \%$ lower than for the greenhouse pre-cultivation treatment. A decrease in yield reduction of this magnitude through adapted genotypes and agricultural management would offer the opportunity of significantly improving the environmental and economic performance of the direct planting of yacon. The production costs per $\mathrm{kg}$ FOS, for example, would decrease by $26 \%$.

In addition to the differences in environmental performance between the two propagation methods, there were also considerable differences in both environmental and economic performance between the different nitrogen fertilization levels. Marine eutrophication is mainly caused by nitrate leaching as a result of nitrogen fertilizer application. Thus, the impact in this category was found to increase with an increase in fertilization level, despite higher yields. This has also been shown in other studies assessing the influence of nitrogen fertilization levels on agricultural production systems [39]. As the use of nitrogen fertilizer had no significant influence on the impact categories agricultural land occupation, freshwater eutrophication, and freshwater ecotoxicity, the increase in FOS yield led to a decrease in the environmental impact in these categories from the 0 to $80 \mathrm{~kg} \mathrm{~N}^{-1}$ level. For the impact categories climate change, human toxicity, and marine ecotoxicity, the picture was more complex. In these categories, the environmental impact per kg FOS of the brown-shelled genotype was comparable in the two fertilization levels 0 and $80 \mathrm{~kg} \mathrm{~N} \mathrm{ha}^{-1}$. The environmental impact of the fertilization level $40 \mathrm{~N} \mathrm{ha}^{-1}$ was significantly higher. This was caused by the only small increase in FOS yield from 0 to $40 \mathrm{~N} \mathrm{ha}^{-1}$ (in the case of the brown-shelled genotype), which led to a less favourable environmental performance of the $40 \mathrm{~N} \mathrm{ha}^{-1}$ treatment per kg FOS produced. The advantage of the $80 \mathrm{~N} \mathrm{ha}^{-1}$ level was related to the fact that not only the tuber yield but also the FOS content increased, resulting in the highest FOS yields. For the red-shelled genotype, there was a slight increase in the categories climate change and human toxicity from the 0 to the $80 \mathrm{~kg} \mathrm{~N} \mathrm{ha}^{-1}$ fertilization level. In the case of human toxicity, the impact was due to nitrogen fertilizer production, and in particular to heavy metals, such as $\mathrm{Cd}, \mathrm{Zn}, \mathrm{Co}, \mathrm{Se}, \mathrm{Hg}$, contained in the fertilizer [40]. In addition to fertilizer production, the impact in the category climate change was caused to a large extent by fertilizer-induced $\mathrm{N}_{2} \mathrm{O}$ emissions and $\mathrm{N}_{2} \mathrm{O}$ emissions resulting from the decomposition of the yacon leaves. In intensive systems with high inputs (e.g., fertilizer), it is quite common that, in the category climate change, the impact per kg output increases despite significant increases in yield [41].

The hotspots of the impacts varied significantly between the environmental impact categories and the life-cycle costs. As demonstrated above, the environmental performance was mainly influenced by fertilizer production and fertilizer-induced emissions. By contrast, the life-cycle costs were dominated by the costs of propagation and of agricultural management. This means there is no easy way to improve the environmental and economic performance simultaneously. As already mentioned, yield increase is one important variable in improving the economic and environmental sustainability. An increase in yield at constant inputs decreased both the environmental impacts [42] and the costs [43] per kg output produced (e.g., kg FOS). Here, the focus should be on the propagation method direct planting, as there is a considerable yield gap between this and the standard procedure.

Another important factor in the environmental performance of the yacon-based FOS production, in addition to fertilizer-induced emissions, was the release of emissions by the decomposition of harvest residues. In the $80 \mathrm{~kg} \mathrm{~N} \mathrm{ha}^{-1}$ treatment, the yacon leaves of the red-shelled genotype contained up to $226 \mathrm{~kg} \mathrm{~N}$ per ha [6] and, according to the IPCC calculation guidelines [28], their decomposition may lead to considerable $\mathrm{N}_{2} \mathrm{O}$ emissions. One way of avoiding these emissions would be to harvest the leaves as a by-product. Yacon leaves could be ensiled to be used as biogas substrate, as has 
already been demonstrated for sugar beet leaves [44]. In addition, yacon leaves contain valuable phytochemicals, such as phenolic and flavonoid compounds [45], which can have anti-microbial and anti-inflammatory properties [46]. Khajehei et al. [47] demonstrated that old leaves of the red-shelled yacon genotypes exhibited a high antioxidant activity level as well as high amounts of certain valuable phytochemicals. It is assumed that the harvest of the leaves should take place as late as possible in order to avoid an adverse effect on tuber formation and thus also tuber yield. Field trials with other root and tuber crops that also store carbohydrates as FOS, such as Jerusalem artichoke, showed that a late harvest is advantageous, as it enables the plant to recirculate macro- and micronutrients from the aboveground back to the underground biomass $[48,49]$. Using the leaves for the production of valuable by-products would also offer an opportunity to significantly improve the economic performance of yacon production.

\subsection{Guidelines for an Economically and Environmentally Sustainable Yacon-Based FOS Production}

Based on the results of this study, it might be concluded that from both an economic and environmental perspective the red-shelled genotype fertilized with the highest rate of $80 \mathrm{~kg} \mathrm{~N} \mathrm{ha}^{-1}$ and propagated in the standard procedure is the most sustainable cultivation system of those analysed. This cultivation system achieved the highest FOS yields per hectare, lowest FOS production costs, and lowest environmental impacts in five of the seven categories assessed. However, future research should focus on the propagation method direct planting, in particular on closing the yield gap to the standard procedure. One method of achieving higher yields in direct planting could be the use of larger rhizomes pieces. Another possibility would be the cultivation of genotypes more suitable for direct planting, for example, those which yield stronger rhizomes or have a faster crop development. Genotype selection also has a significant influence on the environmental and economic sustainability of yacon cultivation, as there are significant differences between genotypes in tuber yield [6,50], sugar content [15,51], as well as phenolic content and antioxidant activity [52]. Therefore, the future success of yacon cultivation is dependent on breeding and cultivating genotypes that are adapted to direct planting and that exhibit both high tuber yield and high FOS content. In addition, for these genotypes more long-term field trials are necessary. The environmental and economic performance assessed in the current study was based on yield data from one year. The data used, however, are comparable to field trials with similar tuber crops such as Jerusalem artichoke, which demonstrated that an increase in nitrogen fertilization leads to an increase in tuber yields [53,54], even though there is more information needed as annual climatic effects, such as changes in precipitation, can have a significant impact on yacon tuber yield formation [6].

Experience with other root and tuber crops, such as Jerusalem artichoke, has shown that, to be economically viable, various parts of the plant need to be used [55]. As discussed above, not only the tubers, but also the leaves should be utilized for the production of high-value products $[45,46]$. The impact of the harvest of leaves as a by-product was not included in this study. However, the cultivation of yacon as a double-use crop with the utilization of these valuable by-products offers an opportunity to significantly improve the economic and environmental performance of yacon cultivation.

With the worldwide prevalence of diabetes likely to rise considerably in coming decades [56], the demand for natural sweeteners that do not lead to an increase in blood glucose level will increase. Yacon, currently a minor crop in Europe, could play a prominent role here, due to its high FOS yield. The results of this study demonstrated that it is possible to select agricultural production systems with comparatively low production costs and impacts on the environment. In addition, they emphasized the importance of an ex ante assessment before a new crop is introduced on a wider scale, and the necessity of including both economic and environmental performance in such assessments.

Supplementary Materials: The following are available online at http:/www.mdpi.com/2071-1050/11/17/4581/s1, Table S1: Costs of agricultural operations, Table S2: Costs of input substrates, Table S3: Biomass transport costs, Table S4: Propagation costs, Table S5: Environmental impacts and production costs per $\mathrm{t}$ FM yacon tubers. 
Author Contributions: Conceptualization: M.W. and L.K.; methodology: M.W.; investigation: M.W.; writing_original draft preparation: M.W. and L.K.; writing—review and editing: I.L. and S.G.-H.

Funding: This study was partly supported by the Bio-Based Industries Joint Undertaking under the European Union's Horizon 2020 Research and Innovation Programme, grant agreement No 745012, and by the German Federal Ministry for Economic Affairs and Energy within the Central Innovation Program for SMEs, grant number 16KN050526.

Acknowledgments: The authors are grateful to Nicole Gaudet for proofreading the manuscript.

Conflicts of Interest: The authors declare no conflict of interest.

\section{References}

1. Zardini, E. Ethnobotanical notes on "Yacon," Polymnia sonchifolia (Asteraceae). Econ. Bot. 1991, 45, 72-85. [CrossRef]

2. Pedreschi, R.; Campos, D.; Noratto, G.; Chirinos, R.; Cisneros-Zevallos, L. Andean Yacon Root (Smallanthus sonchifolius Poepp. Endl) Fructooligosaccharides as a Potential Novel Source of Prebiotics. J. Agric. Food Chem. 2003, 51, 5278-5284. [CrossRef] [PubMed]

3. Valentová, K.; Ulrichová, J. Smallanthus sonchifolius and lepidium meyenii-prospective andean crops for the prevention of chronic diseases. Biomed. Pap. 2003, 147, 119-130. [CrossRef]

4. Bredemann, G. Über Polymnia sonchifolia Poepp. \& Endl. (Polymnia edulis Wedd.), die Yacon-Erdbirne. Bot. Oeconomie. 1948, 1, 65-85.

5. Ojansivu, I.; Ferreira, C.L.; Salminen, S. Yacon, a new source of prebiotic oligosaccharides with a history of safe use. Trends Food Sci. Technol. 2011, 22, 40-46. [CrossRef]

6. Kamp, L.; Hartung, J.; Mast, B.; Graeff-Hönninger, S. Impact of Nitrogen Fertilization on Tuber Yield, Sugar Composition and Nitrogen Uptake of Two Yacon (Smallanthus sonchifolius Poepp. \& Endl.) Genotypes. Agronomy 2019, 9, 151.

7. Choque Delgado, G.T.; da Silva Cunha Tamashiro, W.M.; Maróstica Junior, M.R.; Pastore, G.M. Yacon (Smallanthus sonchifolius): A Functional Food. Plant Foods Hum. Nutr. 2013, 68, 222-228. [CrossRef] [PubMed]

8. Douglas, J.A.; Follett, J.M.; Douglas, M.H.; Deo, B.; Scheffer, J.J.C.; Littler, R.A.; Manley-Harris, M. Effect of environment and time of planting on the production and quality of yacon (Smallanthus sonchifolius) storage roots. N. Z. J. Crop Hortic. Sci. 2007, 35, 107-116. [CrossRef]

9. Valentová, K.; Lebeda, A.; Doležalová, I.; Jirovský, D.; Simonovska, B.; Vovk, I.; Kosina, P.; Gasmanová, N.; Dziechciarková, M.; Ulrichová, J. The Biological and Chemical Variability of Yacon. J. Agric. Food Chem. 2006, 54, 1347-1352. [CrossRef]

10. Graefe, S.; Hermann, M.; Manrique, I.; Golombek, S.; Buerkert, A. Effects of post-harvest treatments on the carbohydrate composition of yacon roots in the Peruvian Andes. Field Crops Res. 2004, 86, 157-165. [CrossRef]

11. Lachman, J.; Fernández, E.C.; Orsák, M. Yacon [Smallanthus sonchifolia (Poepp. et Endl.) H. Robinson] chemical composition and use-A review. Plant Soil Environ. 2003, 49, 283-290. [CrossRef]

12. Campos, D.; Betalleluz-Pallardel, I.; Chirinos, R.; Aguilar-Galvez, A.; Noratto, G.; Pedreschi, R. Prebiotic effects of yacon (Smallanthus sonchifolius Poepp. \& Endl), a source of fructooligosaccharides and phenolic compounds with antioxidant activity. Food Chem. 2012, 135, 1592-1599. [PubMed]

13. Fernández, E.C.; Rajchl, A.; Lachman, J.; Čížková, H.; Kvasnička, F.; Kotíková, Z.; Milella, L.; Voldřich, M. Impact of yacon landraces cultivated in the Czech Republic and their ploidy on the short- and long-chain fructooligosaccharides content in tuberous roots. LWT Food Sci. Technol. 2013, 54, 80-86. [CrossRef]

14. Kamp, L.; Hartung, J.; Mast, B.; Graeff-Hönninger, S. Plant growth, tuber yield formation and costs of three different propagation methods of yacon (Smallanthus sonchifolius). Ind. Crops Prod. 2019, 132, 1-11. [CrossRef]

15. Kamp, L.; Hartung, J.; Mast, B.; Graeff-Hönninger, S. Tuber Yield Formation and Sugar Composition of Yacon Genotypes Grown in Central Europe. Agronomy 2019, 9, 301. [CrossRef]

16. Garnett, T.; Appleby, M.C.; Balmford, A.; Bateman, I.J.; Benton, T.G.; Bloomer, P.; Burlingame, B.; Dawkins, M.; Dolan, L.; Fraser, D.; et al. Sustainable Intensification in Agriculture: Premises and Policies. Science 2013, 341 , 33-34. [CrossRef] [PubMed]

17. ISO Environmental Management_Life Cycle Assessment_Principles and Framework; ISO 14040:2006; ISO: Geneva, Switzerland, 2006. 
18. ISO Environmental Management-Life cycle Assessment-Requirements and Guidelines; ISO 14044:2006; ISO: Geneva, Switzerland, 2006.

19. Huijbregts, M.A.J.; Steinmann, Z.J.N.; Elshout, P.M.F.; Stam, G.; Verones, F.; Vieira, M.; Zijp, M.; Hollander, A.; van Zelm, R. ReCiPe2016: A harmonised life cycle impact assessment method at midpoint and endpoint level. Int. J. Life Cycle Assess. 2017, 22, 138-147. [CrossRef]

20. Wagner, M.; Kiesel, A.; Hastings, A.; Iqbal, Y.; Lewandowski, I. Novel Miscanthus Germplasm-Based Value Chains: A Life Cycle Assessment. Front. Plant Sci. 2017, 8, 990. [CrossRef]

21. Swarr, T.E.; Hunkeler, D.; Klopffer, W.; Pesonen, H.-L.; Ciroth, A.; Brent, A.C.; Pagan, R. Environmental Life Cycle Costing: A Code of Practice; Society of Environmental Toxicology and Chemistry: Pensacola, FL, USA, 2011; ISBN 978-1-880611-87-6.

22. Wernet, G.; Bauer, C.; Steubing, B.; Reinhard, J.; Moreno-Ruiz, E.; Weidema, B. The ecoinvent database version 3 (part I): Overview and methodology. Int. J. Life Cycle Assess. 2016, 21, 1218-1230. [CrossRef]

23. KTBL. KTBL-Feldarbeitsrechner; Kuratorium für Technik und Bauwesen in der Landwirtschaft e. V. (KTBL): Darmstadt, Germany, 2018.

24. Lebeda, A.; Dolezalová, I.; Fernández, E.; Viehmannová, I. Genetic Resources, Chromosome Engineering, and Crop Improvement. Medicinal Plants; Singh, R.J., Ed.; Taylor \& Francis: Boca Raton, FL, USA; New York, NY, USA, 2012; Volume 6, ISBN 978-1-4200-7384-3.

25. Zhang, W.; Liu, X.; Wang, Q.; Zhang, H.; Li, M.; Song, B.; Zhao, Z. Effects of potassium fertilization on potato starch physicochemical properties. Int. J. Biol. Macromol. 2018, 117, 467-472. [CrossRef]

26. Scheffer, J.J.C.; Douglas, J.A.; Triggs, C.M. Evaluation of some pre- and post-emergence herbicides for weed control in yacon. N. Z. Plant Prot. 2002, 55, 228-234.

27. Bouwman, A.F.; Boumans, L.J.M.; Batjes, N.H. Modeling global annual $\mathrm{N}_{2} \mathrm{O}$ and $\mathrm{NO}$ emissions from fertilized fields. Glob. Biogeochem. Cycles 2002, 16, 28-1-28-9. [CrossRef]

28. IPCC. 2006 IPCC Guidelines for National Greenhouse Gas Inventories; Eggleston, H.S., Buendia, L., Miwa, K., Ngara, T., Tanabe, K., Eds.; Prepared by the National Greenhouse Gas Inventories Programme; IPCC: Hayama, Japan, 2006; ISBN 978-4-88788-032-0.

29. EMEP/CORINAIR. Joint EMEP/CORINAIR Atmospheric Emission Inventory Guidebook, 3rd ed.; European Environment Agency: Copenhagen, Denmark, 2001.

30. Nemecek, T.; Kägi, T. Life Cycle Inventories of Swiss and European Agricultural Production Systems; Final report ecoinvent V2.0 No. 15a; Ecoinvent: Zürich, Switzerland; Dübendorf, Switzerland, 2007.

31. Nemecek, T.; Schnetzer, J. Methods of Assessment of Direct Field Emissions for LCIs of Agricultural Production Systems: Data v3.0 2011; Agroscope Reckenholz-Tänikon Research Station (ART): Zürich, Switzerland, 2011.

32. Akiyama, H.; Yan, X.; Yagi, K. Evaluation of effectiveness of enhanced-efficiency fertilizers as mitigation options for $\mathrm{N}_{2} \mathrm{O}$ and $\mathrm{NO}$ emissions from agricultural soils: Meta-analysis: Mitigation options for $\mathrm{n}_{2} \mathrm{O}$ and no emissions. Glob. Chang. Biol. 2010, 16, 1837-1846. [CrossRef]

33. Díez López, J.A.; Hernaiz, P. Effect of a nitrification inhibitor (DMPP) [3,4-dimethylpyrazole phosphate] on nitrate leaching and maize yield during two growing seasons. Span. J. Agric. Res. 2008, 6, 294. [CrossRef]

34. Landwirtschaftskammer Nordrhein-Westfalen; RLV e.V. Erfahrungssätze für überbetriebliche Maschinenarbeiten im Rheinland 2017; Landwirtschaftskammer Nordrhein-Westfalen: Münster, Germany, 2017.

35. Statistisches Bundesamt. Statistisches Jahrbuch Deutschland 2017; Statistisches Bundesamt: Wiesbaden, Germany, 2017; ISBN 978-3-8246-1057-0.

36. Agrarheute.com Düngerpreise. Available online: https://www.agrarheute.com/tag/duengerpreise (accessed on 22 August 2019).

37. Raiffeise. Available online: https://www.raiffeisen-duengershop.de/produkt/obstbau/entec-26/ (accessed on 13 June 2019).

38. Doo, H.S.; Ryo, J.H.; Lee, K.S.; Choi, S.Y.; Cheong, Y.K.; Park, K.H. Response of Different Seedlings to Growth and Yield in Yacon. Korean J. Crop Sci 2002, 47, 356-360.

39. Wagner, M.; Lewandowski, I. Relevance of environmental impact categories for perennial biomass production. GCB Bioenergy 2017, 9, 215-228. [CrossRef]

40. Charles, R.; Jolliet, O.; Gaillard, G.; Pellet, D. Environmental analysis of intensity level in wheat crop production using life cycle assessment. Agric. Ecosyst. Environ. 2006, 113, 216-225. [CrossRef]

41. Goglio, P.; Bonari, E.; Mazzoncini, M. LCA of cropping systems with different external input levels for energetic purposes. Biomass Bioenergy 2012, 42, 33-42. [CrossRef] 
42. Meyer, F.; Wagner, M.; Lewandowski, I. Optimizing GHG emission and energy-saving performance of miscanthus-based value chains. Biomass Convers. Biorefinery 2017, 7, 139-152. [CrossRef]

43. Wagner, M.; Mangold, A.; Lask, J.; Petig, E.; Kiesel, A.; Lewandowski, I. Economic and environmental performance of miscanthus cultivated on marginal land for biogas production. GCB Bioenergy 2019, 11, 34-49. [CrossRef]

44. Parawira, W.; Murto, M.; Zvauya, R.; Mattiasson, B. Anaerobic batch digestion of solid potato waste alone and in combination with sugar beet leaves. Renew. Energy 2004, 29, 1811-1823. [CrossRef]

45. Honoré, S.M.; Genta, S.B.; Sánchez, S.S. Smallanthus sonchifolius (Yacon) leaves: An emerging source of compounds for diabetes management. J. Biol. Res. 2015, 5, 21-42.

46. Oliveira, R.B.; Chagas-Paula, D.A.; Secatto, A.; Gasparoto, T.H.; Faccioli, L.H.; Campanelli, A.P.; Da Costa, F.B. Topical anti-inflammatory activity of yacon leaf extracts. Rev. Bras. Farmacogn. 2013, 23, 497-505. [CrossRef]

47. Khajehei, F.; Niakousari, M.; Seidi Damyeh, M.; Merkt, N.; Claupein, W.; Graeff-Hoenninger, S. Impact of Ohmic-Assisted Decoction on Bioactive Components Extracted from Yacon (Smallanthus sonchifolius Poepp.) Leaves: Comparison with Conventional Decoction. Molecules 2017, 22, 2043. [CrossRef] [PubMed]

48. Somda, Z.C.; McLaurin, W.J.; Kays, S.J. Jerusalem artichoke growth, development, and field storage. II. Carbon and nutrient element allocation and redistribution. J. Plant. Nutr. 1999, 22, 1315-1334. [CrossRef]

49. Swanton, C.J.; Cavers, P.B. Biomass and nutrient allocation patterns in Jerusalem artichoke (Helianthus tuberosus). Can. J. Bot. 1989, 67, 2880-2887. [CrossRef]

50. Fernández, E.C.; Viehmannov, I.; Lachman, J.; Milella, L. Yacon [Smallanthus sonchifolius (Poeppig \& Endlicher) H. Robinson]: A new crop in the Central Europe. Plant Soil Environ. 2006, 52, 564-570.

51. Khajehei, F.; Merkt, N.; Claupein, W.; Graeff-Hoenninger, S. Yacon (Smallanthus sonchifolius Poepp. \& Endl.) as a Novel Source of Health Promoting Compounds: Antioxidant Activity, Phytochemicals and Sugar Content in Flesh, Peel, and Whole Tubers of Seven Cultivars. Molecules 2018, 23, 278.

52. Khajehei, F.; Hartung, J.; Graeff-Hönninger, S. Total Phenolic Content and Antioxidant Activity of Yacon (Smallanthus Sonchifolius Poepp. and Endl.) Chips: Effect of Cultivar, Pre-Treatment and Drying. Agriculture 2018, 8, 183. [CrossRef]

53. Izsáki, Z.; Kádi, G.N. Biomass Accumulation and Nutrient Uptake of Jerusalem Artichoke (Helianthus tuberosus L.). Am. J. Plant Sci. 2013, 4, 1629-1640. [CrossRef]

54. Rodrigues, M.A.; Sousa, L.; Cabanas, J.E.; Arrobas, M. Tuber yield and leaf mineral composition of Jerusalem artichoke (Helianthus tuberosus L.) grown under different cropping practices. Span. J. Agric. Res. 2007, 5, 545-553. [CrossRef]

55. Johansson, E.; Prade, T.; Angelidaki, I.; Svensson, S.-E.; Newson, W.; Gunnarsson, I.; Hovmalm, H. Economically Viable Components from Jerusalem Artichoke (Helianthus tuberosus L.) in a Biorefinery Concept. Int. J. Mol. Sci. 2015, 16, 8997-9016. [CrossRef] [PubMed]

56. Ogurtsova, K.; da Rocha Fernandes, J.D.; Huang, Y.; Linnenkamp, U.; Guariguata, L.; Cho, N.H.; Cavan, D.; Shaw, J.E.; Makaroff, L.E. IDF Diabetes Atlas: Global estimates for the prevalence of diabetes for 2015 and 2040. Diabetes Res. Clin. Pract. 2017, 128, 40-50. [CrossRef] [PubMed]

(C) 2019 by the authors. Licensee MDPI, Basel, Switzerland. This article is an open access article distributed under the terms and conditions of the Creative Commons Attribution (CC BY) license (http://creativecommons.org/licenses/by/4.0/). 